\title{
Féeries
}

Études sur le conte merveilleux, XVII ${ }^{\mathrm{e}} \mathrm{XIX} \mathrm{X}^{\mathrm{e}}$ siècle

\section{Fairy Tales and Feminism, New Approaches}

Detroit, edited by Donal Haase, Wayne State University Press, 2004, $268 \mathrm{p}$.

Jean-François Perrin

\section{(2) OpenEdition}

\section{Journals}

Édition électronique

URL : http://journals.openedition.org/feeries/133

DOI : 10.4000/feeries.133

ISSN : 1957-7753

Éditeur

UGA Éditions/Université Grenoble Alpes

\section{Édition imprimée}

Date de publication : 1 février 2005

Pagination : 306-308

ISBN : 2-84310062-3

ISSN : $1766-2842$

\section{Référence électronique}

Jean-François Perrin, «Fairy Tales and Feminism, New Approaches », Féeries [En ligne], 2 | 2005, mis en ligne le 31 janvier 2007, consulté le 24 septembre 2020. URL : http://journals.openedition.org/ feeries/133; DOI : https://doi.org/10.4000/feeries.133

Ce document a été généré automatiquement le 24 septembre 2020.

(c) Féeries 


\section{Fairy Tales and Feminism, New Approaches}

Detroit, edited by Donal Haase, Wayne State University Press, 2004, $268 \mathrm{p}$.

Jean-François Perrin

1 Cet ouvrage reprend et développe une problématique abordée dans un numéro spécial de la revue Marvels and Tales (14-1:2000) : Tales Liberation - Thirty Years Later, consacré aux études féministes sur le conte de fées. Il s'agit de repenser et de redynamiser de façon critique une approche interdisciplinaire menée depuis près de trente ans sur le conte merveilleux (articles fondateurs d'Alison Lurie: "Fairy Tale Liberation », New York Review of Books, 17 déc. 1970, et Karen E. Rowe: "Feminism and Fairy Tales", Women's Studies 6, 1979). Onze études s'exercent donc à remettre en question les acquis et les méthodes, bousculant quelques idées reçues (les problématiques de la subversion par exemple), réévaluant historiquement les stéréotypes, interrogeant la réception des œuvres, élargissant les corpus à des aires linguistiques nouvelles ou sollicitant l'extrême contemporain et les nouveaux supports de création. Donald Haase présente une histoire critique dense et très informée de trente ans d'études féministes sur le conte de fées. Ruth B. Bottigheimer reprend la question des stéréotypes de l'héroïne de conte à la lumière de leurs antécédents depuis le Moyen Âge, en articulation avec les transformations historiques concernant le contrôle par les femmes de leur fertilité. Lewis C. Seifert reprend la production des conteuses du xvII siècle français, en examinant l'ambiguïté centrale de la représentation qu'elles procurent de l'autonomie individuelle, de la nostalgie, du mariage. Cette mise en question d'une approche trop unilatérale du potentiel subversif de ces contes, résulte également de l'analyse par Jeannine Blackwell de leur réception par les femmes aux XVIII et XIX ${ }^{e}$ siècles. Elizabeth Wannig Harris travaille de son côté sur la façon dont certaines autobiographies féminines après la seconde guerre mondiale, abordent le conte de fées, particulièrement sous l'angle de la question de l'identité féminine. Un essai autobiographique de Kay Stone va également dans cette direction, mettant en lumière le potentiel héroïque de la figure de l'héroïne persécutée. Une série d'études contribue 
ensuite à l'élargissement du corpus des approches d'orientation féministe à d'autres aires linguistiques que celles du français, de l'allemand ou de l'anglais. Patricia-Anne Odber de Baubeta étudie la réception du genre par les écrivains féminins portugais, espagnols et latino-américains ; Fiona Mackintosh propose une synthèse sur le conte de fées dans l'Argentine $\mathrm{du} \mathrm{xx}^{\mathrm{e}}$ siècle, comme forme ironique favorisant une approche critique des identités culturelles (notamment politiques et sexuelles) par les femmes. Lee Haring travaille sur le rôle de la conteuse de tradition orale dans les cultures de l'Océan indien, établissant le rôle médiateur qui est le sien, et montrant qu'on ne peut réfléchir sur la construction des identités sans prendre en compte le rôle de la narration orale dans les cultures vernaculaires. Cristina Bacchilega étudie à travers trois récits indo-anglais contemporains, la critique qu'ils opèrent du stéréotype orientaliste de l'Inde comme terre d'origine du récit merveilleux, en montrant qu'il constitue la partie visible d'une idée mystifiée de la Femme-conteuse. Cathy Lynn Preston enfin, travaille sur les media modernes (du magazine à l'internet) pour analyser l'ambivalence de certaines productions, qui reconduisent parfois sous des formes apparemment critiques, les stéréotypes profonds du genre et l'idéologie patriarcale qui s'y rattache.

2 Ce riche ensemble est complété par un index et une bibliographie quasi exhaustive (dont l'utilité est indiscutable pour qui veut s'informer sérieusement de l'état présent des "gender studies» concernant le conte de fées). Cet ouvrage important signale la vitalité de cette approche critique soucieuse, en ses meilleurs interprètes, de se renouveler par une interrogation ferme de ses acquis et de ses méthodes, ainsi que par l'ouverture de son champ à de nouvelles aires culturelles. 